ARTICLE

DOI: $10.1057 /$ s41599-018-0160-2

\title{
What can policymakers learn from feminist strategies to combine contextualised evidence with advocacy?
}

\author{
Eleanor Malbon (10 1, Lisa Carson² \& Sophie Yates ${ }^{1,3}$
}

\begin{abstract}
We give a short overview of feminist perspectives on the use of evidence in policy making, covering both empirical and conceptual work. We present the case of the Conflict Tactics Scale, a measure of interpersonal violence that is both widely used and heavily criticised in work on violence between intimate partners. We examine this case to illustrate the way that feminist advocacy and research organisations use gender informed theory to counter positivist narratives about intimate partner violence. In doing so, we show that the evidence-based policy approach, even when considered as principle or ideal, frames the policy-making process as "objective", and in doing so ignores the gendered contexts in which knowledge is produced, used and translated into policy and implementation. By examining feminist approaches to this case study, we can learn from feminist advocate researchers the importance of context, normative arguments and the politicisation of evidence in policymaking and implementation.
\end{abstract}

\footnotetext{
${ }^{1}$ University of New South Wales, Sydney, Australia. ${ }^{2}$ University of New South Wales, Canberra, Australia. ${ }^{3}$ Australia and New Zealand School of Government, Melbourne, Australia. Correspondence and requests for materials should be addressed to E.M. (email: eleanor.malbon@unsw.edu.au)
} 


\section{Introduction}

$\mathrm{n}$ a recent Sunday morning, one of our co-authors (Sophie Yates) was walking home with her male partner from the local craft market, having purchased a crusty baguette. Seeing how comically sharp the end of this loaf was, she lunged at her partner as if to stab him in the back with a sword. Unfortunately, he moved at the last moment and instead she rasped the rough edge of the baguette against his arm, drawing blood. He yelped in pain, and understandably got a little irritated with our chastened co-author. The resulting scab took over a week to heal. This incident-which devoid of context, appears to comprise a woman attacking and injuring her male partner with a weapon-can be used to help illustrate a problem with the most commonly used measure of intimate partner violence in population samples: the Conflict Tactics Scale (CTS).

The CTS has been in use for nearly 40 years, and results derived from this measure are used to support claims that women and men are equally violent in intimate relationships, that a focus on gender inequality as a driver of this violence is misplaced, and that policy and practice responses should focus on individualised interventions rather than those based on the way that gender and power shape our society. In this article, we show how feminist advocate researchers have strongly criticised the CTS on theoretical grounds (Nixon, 2007; Allen, 2011; DeKeseredy and Schwartz, 2011), and used research methods sensitive to power and context to empirically draw its validity into question (Currie 1998; Lehrner and Allen 2014; Ackerman 2016). To contextualise this we also give an overview of feminist understandings of evidence, validity of evidence, and evidence in policymaking.

In most established democracies, there is a desire to combine policymaking with evidence, earning a notch of legitimacy for policy and research alike. The use of evidence in policymaking is a good idea, but like many good ideas it is more complicated in practice than it is in theory. It is useful to think of evidence based policymaking (EBP) as a principle or ideal rather than an accomplishable outcome, which allows us to make comparisons between different ideals of EBP (Head, 2010). We can differentiate at least two sorts of ideals about the use of evidence in policymaking (see Cairney, 2016); the first is the 'evidence hierarchy' approach which emphasises objectivity in evidence and downplays the way that politics, theory and values intersect in policymaking (see for example the work of economist and influential Australian politician Andrew Leigh (2010). This approach tends to highlight a 'hierarchy of evidence' to be used in policymaking, starting with randomised controlled trials as the 'gold standard' (Leigh, 2010; Guyatt et al., 1995). What is limiting about the 'evidence hierarchy' approach to policymaking is the model of policy formation that it espouses, which is linear and denotes a 'clean' relationship between evidence and advocacy (Parsons, 2002; Young et al., 2002; Pawson, 2006; Bacchi and Eveline, 2010; Head, 2010; Crammond and Carey, 2017). For example, the 'evidence hierarchy' promotes an ideal of researchers who 'discover' or confirm particular facts that are then passed to advocates who use the information to lobby receptive policymakers for change. However, in practice the process is rarely so smooth. Depictions of a 'clean' or objective relationship between evidence, researchers and policymakers leave little space for the realities of advocacy and normative arguments in politics. This representation of the policy formation process has been critiqued as linear (Young et al., 2002), naïve (Cairney, 2016) and a parody (Marmot, 2004).

We suggest a different approach to evidence and policy, informed by political science and philosophy, which emphasises a theoretically driven approach to evidence production and advocacy (see Wylie, 1987; Anderson, 2004; Cairney, 2016). In this paper, we draw on ideas and theories by feminist philosophers of science, combined with the practices of feminist advocate researchers who critique the use of evidence in domestic and family violence policymaking, to illustrate a politically informed approach to evidence in policymaking. We do not present the approaches taken in our case study as perfect, but seek to discover what we can learn from feminist strategies to combine evidence and advocacy in policymaking. Core among feminist critiques of the naïve EBP approach is that it frames the policymaking process as potentially objective and ignores, specifically, the gendered contexts in which knowledge is produced, used and translated into policy.

\section{Feminist insight into evidence and advocacy}

To understand feminist perspectives and critiques of the use of evidence in policymaking, a brief background in feminist epistemologies of science is required. Feminist philosophies of science offer diverse theories and perspectives on the practice of science, but they are united in their rejection of the popular understanding of scientific objectivity as 'value-free'. Feminist philosophers of science argue that science can never be separated from social influences, and further, that the notion of value-free science should not be held as an ideal. Instead, they argue that science works best when its operating values are acknowledged, examined and utilised effectively to produce good quality scientific work.

Goldenberg (2015) identifies two streams of feminist epistemologies of science: (1) the 'community-based social knowledge' position, spearheaded by Helen Longino and Lynn Nelson, and (2) the 'values as evidence' position, led by Elizabeth Anderson and Sharyn Clough. The distinction is useful because it highlights differences over what constitutes validity of evidence. For the first 'community-based social knowledge' position, Longino (2002) and Nelson (1990) maintain that valid evidence is born of ideal scientific communities that maintain a diversity of viewpoints to uphold objectivity (Goldenberg, 2015). It is important to note that Longino (2002) and Nelson (1990) provide an 'aspirational' picture of scientific inquiry which is not grounded in a value-free ideal, but rather generated through rigorous critical inquiry with a diverse community of researchers who are able to engage in equitable debate and disagreement. To this end, Longino (2002) provides a set of norms for scientific communities that can promote objectivity, such as discursive interaction. Goldenberg (2015) argues that these idealised accounts of scientific communities are not useful in the face of actual scientific communities which do not, practically, function according to these ideals.

For the second 'values as evidence' position, Anderson (2004) and Clough (2003) offer a different understanding of how evidence is considered valid. Anderson argues, along with other feminist empiricists, that value judgements affect the way that evidence is produced, but she goes further to argue that we can determine if the use of value judgements in science is legitimate or not (Anderson, 2004; Goldenberg, 2015). It is important to note that Anderson does not describe science as a mere reflection of power interests, but rather she sets out criteria for determining the legitimacy of value judgements used in scientific inquiry. According to Anderson, the illegitimate application of value judgements in science occurs when values are used to reach a forgone conclusion or dogmatic position (Anderson, 2004). In her case of feminist research on divorce, she demonstrates a legitimate use of gender informed values (and theory) to guide scientific inquiry in support of more contextually informed conclusions (Anderson, 2004). For Anderson, the legitimate use of values in evidence lies in open-ended inquiry, rather than through an appeal to a diversity of viewpoints (in contrast to the 
work of Longino and others in the 'community-based social knowledge' stream).

Intemann (2010) describes what feminist empiricists can learn from feminist standpoint theory, another feminist philosophy of science. Feminist empiricism debates the legitimate use of values in evidence production, whereas feminist standpoint theory extends to the use of evidence in policymaking. Feminist standpoint theory, exemplified by Harding (1987) and Wylie (1987), emphasises that the knowledge included in policy formation should be that which is considered relevant from the standpoint of the subordinate group in a particular situation. Examples of such groups include women, people of colour, non-binary people, people of lower socioeconomic status, survivors of intimate partner violence, and so on. By encouraging the consideration of the standpoint of a subordinate in a particular situation, feminist standpoint theory prioritises context sensitive evidence and the subversion of the 'hierarchy of evidence' approach to policymaking. The feminist standpoint perspective encourages us to consider the perceived legitimacy of evidence in the eyes of policymakers and the public, and what the exclusion of certain evidence reveals about the assumptions and representations of a policy problem (Bacchi and Eveline, 2010). Questions of 'Whose evidence? For what purpose?' should be asked of all attempts to use evidence to influence policymaking (Witkins and Harrison, 2001).

Evidence that is sensitive to gendered contexts. As in the discussion of feminist philosophies of science, feminist critiques of evidence based policy offer a diversity of perspectives on evidence in policy. Some of these feminist critiques align with other critiques of EBP (for example Parsons, 2002), but what is distinct about feminist critiques is their emphasis and sensivitity to the gendered contexts in which evidence is produced and used in policymaking.

Many feminist critiques of the notion of EBP are drawn from feminist critiques of evidence based medicine, from which EBP originated (see Goldenberg, 2015; Rogers, 2004; Davies, 2003). For example, Goldenberg (2015) draws on Anderson's work to show how physicians can choose between legitimate and illigimate medical information without use of the communities of practice espoused by Longino. Rogers (2004) provides a detailed account of the ways in which women's health is marginalised by the evidence based medicine approach, resulting in 'gender blindness' which leaves medical science overwhelmingly focused on women's reproductive health, with less attention paid to other crucial women's health matters such as depression, diabetes, heart disease and HIV/AIDS. Rogers highlights the importance of context, demonstrating that the biomedical model of health that underpins most of the medical research used by EBM ignores the social and political context which contributes so much to the ill-health of women' (2003, p. $50)$.

Davies (2003, p. 1) argues that attempts to work with evidence based practice, and by extension EBP, signify 'death to critique and dissent'. This particular criticism of EBP is levelled at the exclusions that can occur when taking the 'hierarchy of evidence' approach, which has historically excluded marginalised voices in the production of evidence and in decisions about which evidence is considered to be valid for decision making (Davies, 2003). Such silencing of dissent does not fit well with Longino (2002) and Nelson's (1990) ideal depictions of science as comprised of a diversity of viewpoints to uphold objectivity.

Feminist empiricists argue that the value-laden understanding of science has better potential for distinguishing nuanced, context specific science (and evidence) from unsound uses of values in science (and evidence): Anderson's (2004) work on the production of evidence provides tools for explaining why context sensitive research is better than context insensitive work. The value-laden nature of evidence (Anderson, 2004) means that additional critical feminist attention is required to interrogate the ways in which it is and can be used for particular political purposes. Feminist critiques of EBP direct us towards the production and use of evidence that is sensitive to the gendered contexts in which knowledge is produced, used and translated into policy.

The importance of normative argument. Considerations about the validity of evidence have been the focus of feminist empiricist work, but when considering feminist accounts of evidence in EBP we must also consider how evidence is used by advocates in policymaking. Evidence cannot 'speak for itself' in a vacuum of objectivity, it needs political actors to give it voice and meaning. Policymakers and bureaucrats themselves are not likely to mistake the policymaking process as objective or apolitical, rather it is advocates and researchers that have the most to lose by conceptualising the policy process as linear. Crammond and Carey $(2015,2017)$ present empirical work showing that researchers who do not offer a values informed normative argument alongside their evidence run the risk of being ignored. Values, more than evidence, set political agendas because most political problems are in the realm of the normative or moral, such as the promotion of health equity, welfare support or climate change mitigation. However, it is precisely when working within these realms of the normative and moral that 'the accumulation of further evidence is highly unlikely to persuade politicians to act because it necessarily fails to explain why they should be persuaded to act' (Crammond and Carey, 2017, p. 371-372). Researchers who attempt to present only evidence based arguments, and ignore normative based arguments that explain why a politician should act, risk their evidence being ignored or disregarded. Normative argument is the space in which the gender sensitive context of evidence can be explained, and the valueladen nature of this evidence articulated to policymakers.

We now turn to a case study of feminist engagement in the use of evidence in policymaking. We pay explicit attention to the ways that feminist researchers and advocates have highlighted the importance of gender context-sensitive evidence, and normative arguments to accompany evidence, in their critiques of the Conflict Tactics Scale.

\section{The context of counting incidents: feminist empirical critiques of the Conflict Tactics Scale}

This section presents an argument against the validity of contextinsensitive research, using the Conflict Tactics Scale (CTS) as a case study. The CTS has been used extensively in domestic, family and intimate partner violence research, and studies employing it appear to show 'gender symmetry' in violence perpetration. We draw on the theoretical criticisms of the CTS as a blunt instrument missing vital contextual information (such as power dynamics, patterns of behaviour, and perpetrators' and victims' intentions and interpretations), and trace empirical efforts to compare CTS-based research results with those from other methodologies that include this contextual information. When context is added, gender asymmetry in perpetration and experience again emerges, showing the importance of understanding and attempting to measure the contextual gender and power dynamics underlying domestic and family violence.

The story of attempts to measure and respond to violence in families has its roots in the earliest feminist responses to the problem, when women's movement activists worked to expose 
the existence of private gendered violence and make what was commonly termed 'domestic violence' a social issue requiring legislative and policy responses. Previously, domestic violence had been viewed as the private problem of a limited number of 'dysfunctional couples', with victims often doubted and receiving minimal support, and perpetrators experiencing little or no punishment (Renzetti and Bergen, 2005). Early research in this area, coming as it did from a feminist perspective, and focusing on agenda setting and consciousness raising, was mainly qualitative and based on clinical and refuge samples - i.e., participants had by definition experienced significant partner abuse. Unsurprisingly, results supported the feminist viewpoint that domestic and family violence was mainly perpetrated by men in order to control women and their children.

When researchers began using quantitative tools to measure domestic and family violence in the general population (e.g., the US National Family Violence Surveys of 1975 and 1985), the figures appeared to tell a different story (Allen, 2011). A team of researchers at the Family Research Laboratory developed and began using a tool known as the CTS (Straus, 1979). It is based on conflict theory, which sees conflict as an inevitable part of human relationships, and violence as a tactic used to deal with conflict (Straus et al., 1996). Study after study employing the CTS, and later the CTS2 (Straus et al., 1996), found that violence in heterosexual relationships was roughly equally perpetrated by men and women-or even that women were more violent than men. This was unexpected, given that hospital and shelter statistics all indicated that intimate partner violence by men against women constituted the major part of the problem.

The CTS' relative brevity and its ease of administration saw it become the dominant tool for research on the 'prevalence, predictors, correlates, outcomes, and treatment of IPV [intimate partner violence]' (Lehrner and Allen, 2014, p. 477). By 2002, more than 100 empirical studies using the CTS or similar tools supported the gender symmetry hypothesis (Kimmel, 2002). Straus (2007) reported that between 1973 and 2005, approximately 600 papers and at least 10 books had been published based on the CTS. Two US National Family Violence Surveys (1975 and 1985) had also been based on the CTS, and were subject to considerable secondary analysis, forming the basis of much theorising (Walby and Myhill, 2001). But perhaps the most influential publication supporting the gender symmetry hypothesis has been Archer's (2000) meta-analysis of studies totalling n60,000, most of which had used the CTS- with only a small number of studies using any other type of quantitative measure. Archer concluded that although the effect size was small and women suffered more severe injuries than men, 'women were significantly more likely than men to have used physical aggression toward their partners and to have used it more frequently' (p. 664).

As a consequence of these studies, many researchers reject feminist theories of intimate partner violence in favour of other explanations such as individual psychopathology or intergenerational transmission (learned behaviour) (Corvo and Johnson, 2013). This is the context for more than ' 30 years of sometimes acrimonious scholarly debate' over whether domestic and family violence is gender symmetrical (Johnson, 2005, p. 1129; Dutton, 2010).

For as long as the CTS has been in use, feminist activist researchers have been criticising its validity (Myhill, 2017). The main criticism is that it misses-and in fact is not intended to measure-contextual factors that are crucial to establishing patterns of coercive control (Allen, 2011; Nixon, 2007). According to Currie (1998), researchers from the family conflict tradition consistently 'obscure the importance of gender' (p. 101) and its implications for existing power dynamics in intimate relationships, assuming that violence stems from conflict and that parties in conflict are equally powerful. The CTS asks participants to report the use or experience of 39 verbally/emotionally or physically violent behaviours in response to a conflict or anger situation during the previous 12 months. Instructions to participants ask them to think about different ways couples have of settling their differences, or spats and fights (Straus et al., 1996). Crucially, critics note that it counts the number of incidents but does not record the substantive issue that led to the violence, or any other pertinent context (Allen, 2011; Braaf and Meyering, 2013). There is no way to report whether incidents occurred in the context of self-defence, or assess the impact of violent incidents (although a scale was added in the CTS2 with the aim of measuring injury levels) (Hester et al., 2010). It also instructs respondents to consider only conflict or argument-instigated violence, revealing the assumption that all violence is used expressively, i.e., in anger and thus potentially missing instrumental violence used to control individuals, and violence that doesn't stem from an identifiable cause (Flood, 2006; DeKeseredy and Schwartz, 2011). Patterns of instrumental violence, also known as 'coercive control' or 'intimate terrorism', have been shown by many researchers to be overwhelmingly gendered (Anderson, 2009; Johnson, 2005).

Further, it overlooks a continuum of violence and excludes commonly-recognised abusive behaviours such as economic abuse, isolation of victims, manipulation involving children, and stalking (DeKeseredy and Schwartz, 2011). Post-separation violence, which is a major component of domestic and family violence, especially for women (Kimmel, 2002; Hester, 2011), is not measured by the CTS (Flood, 2006). Finally, the CTS does not measure fear or intimidation, which many studies have found to be a significant component of domestic and family violence (Allen, 2011). In the words of Flood (2006), due to the 'highly decontextualised and abstracted' treatment of violence by the CTS, 'this acts-based method actually produces findings of gender equality in domestic violence' (p. 3).

To further their arguments that theories of domestic and family violence (and thus policy responses) should not be based solely on the data derived from the CTS, a number of feminist researchers have conducted research combining it with qualitative methods, or other methods that add contextual information. In doing so, their aim is to call the CTS' validity into question using empirically based rather than epistemological critiques. When these methods are used, gender asymmetry again emerges. For example, feminist sociologist Dawn Currie (1998) added openended questions to the CTS, inviting participants to provide detailed accounts of violent incidents that otherwise would have been counted as abstract events. The men in her sample reported proportionally more violent incidents from female partners than the women from their male partners, as is the case in many studies employing the CTS. However, the added context enabled her to determine that men 'upgraded' women's use of violence, while women tended to downplay men's use of violence, blaming themselves and excusing men's violence as 'understandable' ( $\mathrm{p}$. 106). Several incidents described by women were interpreted or intended as play by their partners, but not by the women themselves. In addition, violence from women that men considered to be amusing or at most annoying appeared in the CTS results, and without this contextual information would have been counted the same way as violence viewed as serious. Currie (1998) argued that these results provide empirical grounds to question the CTS' ability to accurately measure either the extent or the nature of violence in heterosexual relationships.

Hilton et al. (2003) found in their study of interpersonal violence among high school students that the CTS yielded comparable (and gender-symmetrical) rates of violence in their 
sample as found in other large-scale studies of adolescents. They compared CTS results to a second measure of violence, in which students listened to fictional but lifelike scenarios of physical, emotional or sexual violence. In response to the scenarios, both boys and girls reported much lower rates of violence than found by the CTS-in other words, these results suggested that the CTS had produced over-reporting of violence. Even though both boys and girls reported lower rates of violence in this second research measure, there were sex differences: boys reported more violence perpetration than girls-especially for physical violence. The authors reported that: 'Consistent with statistics from police and hospitals (with respect to all violence) as well as from shelters (with respect to relationship violence), the scenario method suggested men are the more aggressive sex (p. 234).'

Ackerman (2016) took a different angle on the issue of overreporting thought to be generated by the CTS. He used insights from the cognitive interviewing literature; ${ }^{1}$ studies from this research tradition have shown that different interpretations of the meaning of survey questions (either different from each other or different from what the survey designer intended) can result in over-reporting, under-reporting, or both. Ackerman (2016) applied these insights to the CTS, inquiring of participants whether the incidents they had just described were accidents or 'joking, playful or humorous' (p. 657). He categorised incidents where these two responses were selected as 'over-reports'-as would have been the case with the baguette incident described in the introduction to this paper. Ackerman (2016) found significant over-reporting of both perpetration and victimisation from his male participants:

... males are more likely than the females to respond affirmatively in a way unintended by the survey design [and] the males do this far more often when asked whether a female has victimised them compared with when asked whether they have victimised a female (perpetrated an [intimate partner violence] event against a female) (p. 662).

Most interestingly, Lehrner and Allen's (2014) groundbreaking study combining the CTS2 with qualitative interviews throws the CTS' construct validity into more doubt. Noting Straus et al.'s (1996) insistence on the CTS2's applicability for university student populations, Lehrner and Allen (2014) administered the questionnaire to 476 undergraduate women. They expected that, consistent with the CTS-based literature, about half the sample would report some level of intimate partner violence perpetration, and this was the case. The authors then grouped the women into categories based on frequency and severity of selfreported violence, ranging from level 1 (no violence) to level 4 (minor violence $6+$ times or any severe violence). To contextualise participants' CTS data, the authors conducted in-depth interviews with a random sample from each category, including 'questions about the setting, precipitating events and emotions, motives, and outcomes for any reported incidents' (p. 479). Their qualitative results showed large discrepancies with the CTS data, including misclassification of victimisation as perpetration; misidentification of mutual violence when in fact there was a victim/ perpetrator dynamic; and-crucially-high levels of 'mock' (joking) or 'playful' (fun physical sparring) violence that had often been coded by the CTS as 'severe' violence.

Of the 10 women interviewed who were classified by the CTS as severe perpetrators, two had only used violence in self-defence, one had been severely victimised, one had used only playful violence (again the baguette comes to mind), and the others reported a combination of mock, playful and meaningful violence (p. 483). The discrepancy in categorisations between interview and CTS data affected $58 \%$ of the interview participants coded as violent by the CTS (p. 484), leading to substantial doubts about whether the CTS is actually measuring what it claims to measure. Indeed, Myhill (2017) throws doubt on the ability of people subject to ongoing abuse and coercive control to accurately remember discrete incidents at all:

This conceptualisation assumes that victims view every aspect of the abuse they experience as discrete and to some degree time-bound. ... While acts of physical violence may sometimes be discrete enough to recall and 'count', wider abuse and especially the sense of entrapment is most often described as multifaceted, 'continuous' and not amenable to being counted as discrete acts or episodes (p. 40).

Described as 'feminist-advocate' researchers by Myhill (2017), it is clear that the work of these researchers is not intended merely to clarify discrepancies between different methods of measurement. They are keenly aware of the use to which research evidence on intimate partner violence is put, and seek to promote policies that take into account the inequalities and contextual factors that drive this violence. For Currie (1998), 'at stake is the provision of victim support services for battered women' (p. 99) and she notes that claims of gender symmetry in intimate partner violence had led to the reduction or blocking of services for battered women in at least two US states. Ackerman (2016) argues that gender differences in intimate partner violence overreporting have serious implications because survey evidence affects public awareness of the problem, as well as public policy and response to the problem. He felt his results suggested that several feminist theoretical claims not previously supported by empirical data-such as the potential for the CTS to produce over-reporting-now deserve re-evaluation using 'methods that can potentially ameliorate over-reporting and other forms of systematic measurement error' (p. 662). The re-evaluation of theoretical claims based on empirical data (that was developed based on those theoretical claims) is the sort of evidence production advocated for by Anderson (2004) and the 'values as evidence' position of feminist empiricism (Goldenberg, 2015). Lehrner and Allen (2014) further argue:

Given the social significance of [intimate partner violence] and the prevention, treatment, and policy implications of its accurate assessment, continued investigation into the validity of the CTS with diverse populations and the further development of more nuanced and developmentally sensitive assessment strategies appears warranted (p. 488).

Nor do feminist advocates seek to throw the quantitative baby out with the methodological bathwater. As DeKeseredy (2016) notes in his article on the enduring relevance of feminist thought for measuring and understanding intimate partner violence, feminist scholars have led advances in victimisation survey research over the past 30 years. An example is 'progressive survey researchers' Michael Smith and Rebecca and Russell Dobash, whose contribution to the development of the Canadian National Violence Against Women Survey sought to place intimate partner violence in context to explore its meaning and impact (DeKeseredy, 2017; Walby and Myhill, 2001). With modifications, this model was subsequently used in Australia, Finland, Iceland, Sweden, Germany and Ireland (Walby and Myhill, 2001). More recently, Walby et al. (2017) have argued for the measurement of 'gender saturated' dimensions of interpersonal violence as a way to improve the contextual information collected by measurement approaches based on acts of violence.

The difference between feminist and non-feminist researchers and mainstream intimate violence researchers is not that they advocate for one particular method or that they eschew quantitative measurement. Rather, it is that they strive to be sensitive to power and context, do not pretend that their research is (or could 
be) objective or value free, and produce work that is theorydriven rather than the "abstracted empiricism" common to many studies on intimate partner violence (DeKeseredy, 2016, 2017). This point was also made nearly two decades earlier by Currie (1998), who observed that the use of the CTS has been largely research-led rather than theory-driven (although the measure itself was originally derived using theoretical insights from conflict research). In fact, CTS pioneer Richard Gelles wrote in 1983 that the use of 'ideology'-meaning theories about the role of sexism and racim in domestic violence-had 'partially inhibited a serious scientific program of theory construction in this area' (p. 154). As Breines and Gordon (1983) point out, this contrasts his own 'empiricist' method of theory construction with other methods of theory construction which he finds 'ideological' and hence non-scientific, and not supported by the available empirical evidence. It indicates that accompanying the introduction of the CTS may have been notions of scientific purity and objectivity intended to counter ideologically-driven research based on gendered understandings of the problem. DeKeseredy and Dragiewicz (2013) concur, arguing that this absence of theory in intimate partner violence research is linked to calls for 'evidence based practice' in criminology, an approach which has been used 'to target feminist theories as political rather than scientific', and which claims to be atheoretical but instead works to obscure implicit theoretical assumptions (p. 303-304).

While the CTS has been extensively critiqued before, both theoretically and methodologically, the account of the 'gender symmetry' debate provided here brings the feminist theoretical criticisms together with the work of scholars who have applied these principles empirically to produce results that throw the construct validity of the CTS into doubt. We have shown that this was done not just in service of discovering the true nature of intimate partner violence, but because theories of what causes intimate partner violence affect the policies implemented to address them, and thus affect social outcomes. In the following section we show how, in a recent Commission of Inquiry, feminist advocate researchers have drawn on this contextually-driven research to refute claims of gender symmetry in intimate partner violence and ward off policy responses that assume most intimate partner violence is mutually perpetrated.

\section{The CTS and the gender symmetry debate in Australian Parliament}

Debates about the validity of the CTS as a measure for intimate partner violence, and the validity of the gender symmetry argument more broadly, were triggered in Australian politics in the 2014-2015 Senate Inquiry into Domestic violence in Australia (hereafter: the Inquiry) (FPARC, 2015). During the Inquiry, representatives for the men's rights activist group One in Three used Straus' work and evidence derived from the CTS measure to justify their claims that most family violence is mutual or 'common couple' violence. The following excerpt is from the official Australian Government Hansard transcript of the Inquiry:

Senator Waters: I want to take you to that part of your submission where you contend that patriarchy is not a factor in the present levels of domestic violence. You make a statement:

'Most family violence is called "common couple violence" in which the violence is committed by both people...'

That seems to me to swim against the tide of most of the evidence that we have received to date. What is your basis for suggesting that violence is mutual?
$\mathrm{Mr}$ Andresen [One in Three]: It is 30 years of family violence research. I would be happy to take that question on notice and provide you with study after study that shows that (Official Committee Hansard, 2014, p. 29).

Here, Andresen is clearly referencing the family conflict stream of research discussed in the previous section to argue that patriarchy is not a factor in domestic violence and that violence in couples is generally mutual. One in Three's (2014) submission to the Inquiry relies heavily on the work of Straus, Gelles and other CTS researchers. Andreson refers specifically to work by "the very long-term and highly esteemed family violence researcher Murray Straus" in support of his oral evidence (Official Committee Hansard, 2014, p. 28).

However, the presentation of Straus's work and the CTS measure was anticipated and met by feminist organisations present at the Inquiry. A representative from the feminist organisation ANROWS (Australia's National Research Organisation for Women's Safety) identified use of the discredited CTS measure and the gender symmetry argument:

Dr Mayet Costello: One of the key uses of data that organisations like One in Three use when they talk about gender symmetries-when they say violence is equal between men and women-is work that was done in the United States under the [CTS], which has been widely discredited across the research community for two reasons. One, the scale does not take into account context, so it does not take into account, for example, the use of retaliatory violence or violence in self-defence compared to violence that is for the purpose of controlling, intimidating or causing fear against the other party. The other key thing it fails to do is recognise either harm or the disparity between different types of violence. To use a very simple example, a slap on the hand might be considered equivalent to a punch to the face. So, whereas the potential damage done to those two activities are substantial, if you put it in the context of intent, it is very problematic (Official Committee Hansard, 2014, p. 4).

Part of ANROWS' strategy as a feminist advocate organisation is to highlight that the men's rights activist group is drawing on discredited evidence, and provide argument for the use of evidence from measures that take the context of violent incidents into account. Coupled with this strategy is the presentation of normative argument as to why the Inquiry should recommend resources and research funding for domestic violence against women. Their politicisation of evidence and the presentation of normative argument gives the feminist advocate organisation influence and legitimacy in the Inquiry room:

Dr Costello: the gender symmetry debate is... exactly the same debate we have in terms of why we are producing evidence and why we want to have the best evidence of where we should direct our funding. Resources should really be directed towards where they are of most need, and we have an overwhelming quantum of evidence which shows that violence against women is prevalent and has huge impacts... The statistics as we know them now do not currently support the position that those organisations take who argue gender symmetry (Official Committee Hansard, 2014, p. 5).

The final Inquiry report did acknowledge the need to give support to male victims of domestic and family violence, but it also accepted ANROWS' analysis that women are most likely to experience violence in the home by a current or former partner, and men outside the home by strangers, acquaintances or 
neighbours (FPARC, 2015). It also featured ANROWS' argument that the contributors to violence are complex and include "attitudes to women and gender roles within relationships, family and peer support for these attitudes, and social and economic gender inequality in the broader societal context" (p. 5). Included in the Inquiry's list of recommendations is to secure at least seven years of funding to ANROWS to continue their research work, an accomplishment for the feminist research organisation (FPARC, 2015, p. ix).

The response of the Senate Committee does not show support for the arguments of gender symmetry and the CTS measure. It does not suggest that violence in families is largely mutual or gender symmetrical, and refers constantly to the work of gendersensitive organisations ANROWS and Our Watch. This demonstrates the contribution of feminist advocates and feminist researchers to domestic and family violence debates in Australia. As described in the introduction, the feminist perspective encourages examination of the gendered contexts of evidence, and leads us to question the perceived legitimacy of evidence in the view of policy makers, who often define the boundaries of a policy problem (see Bacchi, 1999; Carson and Edwards, 2011). In the case of the gender symmetry debate in Australia, feminist advocacy organisations and committee members ensured that the claims of One in Three and the CTS measure were scrutinised in order to highlight a framing of domestic and family violence that takes the context of violent events into consideration. In line with Anderson's (2004) advocated approach, ANROWS showed that their evidence is more legitimate than the CTS based evidence because it is theory-driven and has better explanatory power in accounting for the gender dynamics at play. The success of this strategy is shown through the recognition that the people most vulnerable to domestic and family violence in Australia are women, especially Indigenous women, women with disability and women from culturally and linguistically diverse backgrounds.

\section{Discussion}

We have outlined common critiques of EBP, and presented a feminist informed account of the role of advocacy in the evidence and policy interface. We drew on seminal texts in public policy and feminist literature to form a theoretical basis that highlights i) the importance of evidence that is sensitive to gendered contexts and ii) the importance of normative arguments in EBP. Feminist thought calls critical attention to the structure and nature of gendered power relations (Kelly, 2000) as well as the performance of gender in social situations (Butler, 1988) and as such the gendered context of policy problems remains a central concern for feminist critiques of evidence and policy. To illustrate this, we examined how feminist researchers have interacted with a problematic measure of intimate partner violence (the CTS) that is both widely used and widely critiqued, and is often employed to support arguments about 'gender symmetry' in intimate partner violence. Feminist advocate researchers have worked to discredit the CTS and gender symmetry arguments, to ensure that policymaking draws upon a more richly contextualised understanding of intimate partner violence. This is not simply a case of choosing the 'right' sort of evidence to draw on in the formation of policy; the case of feminist engagement with intimate partner violence research demonstrates that feminist researchers strive to be sensitive to power and context, are explicitly normative, and produce evidence that is theory-driven rather than the 'abstracted empiricism' that is common to much positivist research (Anderson, 2004; DeKeseredy, 2016; 2017; Goldenberg, 2015).

It would not have been enough for feminist researchers to simply present an alternative measure to the CTS. The accumulation of 'more' evidence or 'alternative' facts necessarily fails to explain to policy makers how to make decisions and why to act on policy issues (Crammond and Carey, 2017). In the case of intimate partner violence, feminist researchers could not simply present a different measure such as Dobash and Dobash's (2004) context-sensitive measure of intimate partner violence without accompanying their evidence with normative arguments about the value of treating intimate partner violence as a gendered issue. Simply supplying or pointing out the alternative measure would fail to convince policy makers why they should consider the CTS measure as discredited, why they should consider intimate partner violence to be a gendered issue, and why they should make policy accordingly. The combination of the use of normative arguments alongside the presentation of more accurate measures of intimate partner violence (Dobash and Dobash, 2004) is what has progressed the conversation on intimate partner violence towards gender and context sensitivity in the evidence and policy interface. Importantly, the reason that studies based on the Dobash and Dobash (2004) measure are more accurate and constitute better evidence of intimate partner violence is because of their legitimate use of gender informed values (and theory) to reach more contextually informed conclusions (Anderson, 2004).

The use of evidence by researchers who employ the CTS measure and the gender symmetry argument matches Parsons general observations about the 'hierarchy of evidence' approach to EBP: their aim is "to de-politicise and managerialise knowledge production and its utilisation" (Parsons, 2002, p. 56) in the debate, while also de-emphasising the importance of gendered contexts in the presentation of evidence regarding intimate partner violence. In contrast, feminst advocates draw attention to the shortcomings of the CTS measure by critiquing it both theoretically and empirically, and through the development of measures that do collect gender contextual evidence about incidents of intimate partner violence (DeKeseredy, 2017; Walby and Myhill, 2017). Feminist advocates used a gendered analysis to politicize the use of the CTS measure, allowing for critique of its use to support the gender symmetry argument in policy formation and implementation. In this way, we see that feminist advocate organisations are able to work against the silencing of dissent identified in Davies (2003) and attempt to widen the boundaries around what is considered to be legitimate knowledge for policymaking (Bacchi, 1999).

As highlighted in the introduction, from a feminist standpoint perspective (Wylie, 1987; Harding, 1987) the political tussle over what evidence is considered to be relevant for policy formation should be informed by knowledge relevant to those in subordinate positions of power, such as the targets of intimate partner violence (who, research shows, are more likely to be women). We examined the strategy of feminist organisation ANROWS in addressing and countering a narrative of gender symmetry in the Senate inquiry into domestic violence in Australia. This case illustrates that the combination of normative arguments and the gendered politicisation of evidence can be used to convince policymakers that certain quantitative measures are not reliable, and that resources to care for victims of domestic violence should be focussed on the women, and particularly the most vulnerable populations of women, in Australia. Other recent Australian commissions of inquiry (e.g., the Victorian Royal Commission into Family Violence and the Special Taskforce on Domestic and Family Violence in Queensland) have since reiterated the problem framing of domestic and family violence (of which intimate partner violence is the most common form) as primarily perpetrated by men against female partners and their children. This is thanks in large part to the work of committed feminist advocate researchers who refuse to accept that evidence can or should be decontextualised or depoliticized. 


\section{Conclusion}

Feminist theorists and practitioners draw attention to the importance of anticipating and applying a feminist understanding to both policy formation and outcomes by using multiple levels of analysis, such as individual, collective and structural, as well as analysing differential impacts across intersecting axes including gender, race, sexuality, ability, and religion among others. Doing so can reveal additional layers of complexity that may otherwise be overlooked. Whilst all violence is wrong, regardless of the sex of the perpetrator, there are distinct gendered patterns in the perpetration and impact of violence. Work by critical feminists, practitioners, and men and masculinities scholars has shown that there may be similarities between male and female perpetrated violence, but they are not the same, because the causes, dynamics and outcomes of violence against women are different from those of violence against men (Yates, 2018; Read-Hamilton, 2014; Kelly, 2000). For example, men may fear and suffer violence from predominantly other men and some individual women, whereas women tend to face more widespread violence, both individually and structurally (Kelly, 2000; Kilmartin and Allison, 2007). The ability to interrogate policy framings and outcomes using different levels of analysis is necessary to ensure that we achieve more politically informed and context-specific understandings of policy 'problems' and proposed 'solutions'.

In the introduction to this piece we made a distinction between 'evidence hierarchy' approaches to EBP which downplay politics and context, and a politically and contextually informed approach to thinking about EBP. The case of feminist engagement with the CTS provides an example of a gender political and contextually informed approach to EBP. Specifically, feminist researchers engaged with questions of the legitimacy of evidence. Their approach is an example of the 'open inquiry' that is espoused by Anderson and other feminist empiricists that consider evidence to always be value-laden, and that value-laden evidence can be used in legitimate or illegitimate ways (Anderson, 2004). We claim that the case of the CTS aligns with Anderson's approach to evidence production; feminist researchers questioned the validity of the evidence that was being produced in intimate partner violence research because of their concerns about the gendered contexts of intimate partner violence. Through their value-laden motivations, and their articulation of these values, they have created a more contextualised understanding of what might be considered to be legitimate or 'gold standard' evidence when considering intimate partner violence. We have shown that feminist theory and practice in the combination of evidence in policymaking emphasises the need for contextualised, theory driven approaches to the policy evidence, and the importance of normative arguments when advocating for policy change. In the words of Anderson:

"Value judgments guide inquiry toward the concepts, tools, and procedures it needs to answer our value-laden questions. But facts - evidence - tell us which answers are more likely to be true. These two roles must be kept distinct, so that inquiry does not end up being rigged simply to reinforce our evaluative preconceptions" (Anderson, 2004, p. 23).

We can recall, for the final time, the baguette incident: While it is a fact that Sophie injured her male partner with a baguette, it is clear that the injury did not occur in malice but in jest and accident, highlighting the importance of understanding the context of violent incidents in our attempts to measure them.
Received: 6 February 2018 Accepted: 7 August 2018

Published online: 28 August 2018

\section{Notes}

1 Cognitive interviewing involves asking participants to complete a survey and then interviewing them about their answers.

\section{References}

Ackerman JM (2016) Over-reporting intimate partner violence in Australian survey research. Br J Criminol 56(4):646-667

Allen M (2011) Is there gender symmetry in intimate partner violence? Child Fam Social Work 16(3):245-254

Anderson KL (2009) Gendering coercive control. Violence Women 15 (12):1444-1457

Anderson E (2004) Uses of value judgments in science: A general argument, with lessons from a case study of feminist research on divorce. Hypatia 19(1):1-24

Archer J (2000) Sex differences in aggression between heterosexual partners: a meta-analytic review. Psychol Bull 126(5):651-680

Bacchi CL, Eveline J (2010) Mainstreaming politics gendering practices and feminist theory. University of Adelaide Press, Adelaide

Bacchi CL (1999) Women, policy and politics: the construction of policy problems. Sage, London

Braaf R and Meyering IB (2013) The gender debate in domestic violence: the role of data Issues Paper No. 25. Australian Domestic \& Family Violence Clearinghouse, Sydney

Breines W, Gordon L (1983) The new scholarship on family violence. Signs 8 (3):490-531

Butler J (1988) Performative acts and gender constitution: an essay in phenomenology and feminist theory. Theatre J 40(4):519-531

Cairney P (2016) The politics of evidence-based policy making. Palgrave Macmillan, London

Carey G, Crammond B (2015) Systems change for the social determinants of health. BMC Public Health 15:662

Carson L, Edwards K (2011) Prostitution and sex trafficking: What are the problems represented to be? A discursive analysis of law and policy in Sweden and Victoria, Australia. Aust Fem Law J 34(1):63-87

Clough S (2003) A hasty retreat from evidence: The recalcitrance of relativism in feminist epistemology. In: Clough (eds) Siblings under the skin: feminism, social justice and analytic philosophy. The Davies Group, Aurora, p 85-116

Corvo K, Johnson P (2013) Sharpening Ockham's razor: The role of psychopathology and neuropsychopathology in the perpetration of domestic violence. Aggress Violent Behav 18(1):175-182

Crammond B, Carey G (2017) Policy change for the social determinants of health: the strange irrelevance of social epidemiology. Evid Policy A J Res Debate Pract 13(2):365-374

Currie DH (1998) Violent men or violent women? Whose definition counts? In: Bergen RK (ed) Issues in Intimate Violence. Sage, Thousand Oaks, p 97-113

Davies B (2003) Death to critique and dissent? The policies and practices of new managerialism and of 'evidence-based practice'. Gend Educ 15(1):91-103

DeKeseredy WS (2016) Understanding woman abuse in intimate heterosexual relationships: the enduring relevance of feminist ways of knowing. J Fam Violence 31(8):1043-1046

DeKeseredy WS (2017) Using crime surveys as tools of critical insight and progressive change. In: Jacobsen MH, Walklate S (eds) Liquid criminology: doing imaginative criminological research. Routledge, London, p 31-48

DeKeseredy WS, Dragiewicz M (2013) Gaps in knowledge and emerging areas in gender and crime studies. In: Renzetti CM, Miller SL, Gover AR (eds) Routledge international handbook of crime and gender studies. Routledge, Oxon, p 297-307

DeKeseredy WS, Schwartz MD (2011) Theoretical and definitional issues in violence against women. Sourceb Violence Women 2:3-22

Dobash RP, Dobash RE (2004) Violence to men in intimate relationships: working on a puzzle. Br J Criminol 44(3):324-349

Dutton DG (2010) The gender paradigm and the architecture of antiscience. Partn Abus 1(1):5-25

FPARC Finance and Public Administration References Committee (2015) Senate inquiry into domestic violence in Australia. Commonwealth of Australia, Canberra

Flood M (2006) The debate over men's versus women's family violence. Australian Institute of Judicial Administration Family Violence Conference, Adelaide, $p$ 23-24

Gelles R (1983) An exchange/social control theory. In: Finkelhor D, Gelles RJ, Hotaling GT, Straus MA (eds) The dark side of families: current family violence research. Sage, Thousand Oaks, CA, p 151-165 
Goldenberg M (2015) How can feminist theories of evidence assist clinical reasoning and decision-making? Social Epistemol 29(1):3-30

Guyatt G, Sackett D, Sinclair J, Hayward R, Cook D, Cook R (1995) Users' guides to the medical literature. IX. A method for grading health care recommendations. Evidence-Based Medicine Working Group. J Am Med Assoc 274 (22):1800-1804

Harding S (1987) The science question in feminism. Cornell University Press, Ithaca, London

Head B (2010) Evidence-based policy: principles and requirements. In Strengthening evidence-based policy in the Australian Federation. Productivity Commission, Melbourne, p 13-26

Hester M (2011) The three planet model: towards an understanding of contradictions in approaches to women and children's safety in contexts of domestic violence. Br J Social Work 41(5):837-853

Hester M, Donovan C, Fahmy E (2010) Feminist epistemology and the politics of method: surveying same sex domestic violence. Int J Social Res Methodol 13 (3):251-263

Hilton NZ, Harris GT, Rice ME (2003) Correspondence between self-report measures of interpersonal aggression. J Interpers Violence 18(3):223-239

Intemann K (2010) 25 years of feminist empiricism and standpoint theory: where are we now? Hypatia 25(4):778-796

Johnson MP (2005) Domestic violence: it's not about gender: Or is it? J Marriage Fam 67(5):1126-1130

Kelly L (2000) Wars against women: sexual violence, sexual politics and the militarised state. In: Jacobs S, Jacobson R, Marchbank J (eds) States of conflict: gender, violence and resistance. Zed Books, London, p 45-65

Kilmartin C, Allison J (2007) Men's violence against women: theory, research and activism. Lawrence Erlbaum Associates, New Jersey

Kimmel MS (2002) Gender symmetry in domestic violence: a substantive and methodological research review. Violence Women 8(11):1332-1363

Lehrner A, Allen NE (2014) Construct validity of the conflict tactics scales: a mixed-method investigation of women's intimate partner violence. Psychol Violence 4(4):477-490

Leigh A (2010) Evidence-based Policy: Summon the Randomistas? In: Strengthening evidence-based policy in the Australian Federation, Roundtable Proceedings, Productivity Commission, Canberra, pp 215-226

Longino H (2002) The fate of knowledge. Princeton University Press, New Jersey

Marmot M (2004) Evidence-based policy or policy based evidence? Br Med J 328 (7445):906-907

Myhill A (2017) Measuring domestic violence: context is everything. J Gend-Based Violence 1(1):33-44

Nelson L (1990) Who knows: from Quine to feminist empiricism. Temple University Press, Philadelphia

Nixon K (2007) The power to name: conceptualizing domestic violence as violence against women. Currents 6(1):1-24

Official Committee Hansard (2014) Senate Inquiry: domestic violence in Australia. Commonwealth of Australia. http://parlinfo.aph.gov.au/ Accessed 1 Oct 2017

One in Three (2014) Submission to the Senate Standing Committees on Finance and Public Administration's inquiry into domestic violence in Australia. Commonwealth of Australia. https://www.aph.gov.au/DocumentStore.ashx?id=85261703c49e-4dbe-b2a6-239ad19a53ea\&subId=298424. Accessed 1 Oct 2017

Parsons W (2002) From muddling through to muddling up-evidence based policy making and the modernisation of British Government. Public Policy Adm 17 (3):43-60

Pawson R (2006) Evidence-based policy: a realist perspective. Sage, London

Read-Hamilton S (2014) Gender-based violence: a confused and contested term. Humanitarian Exchange Magazine. https://odihpn.org/magazine/genderbased-violence-a-confused-and-contested-term/. Accessed 20 Nov 2017
Renzetti CM, Bergen RK (2005) Violence against women. Rowman \& Littlefield, Maryland

Rogers W (2004) Evidence-based medicine and women: do the principles and practice of EBM further women's health? Bioethics 18(1):50-71

Straus MA, Hamby SL, Boney-McCoy S, Sugarman DB (1996) The revised Conflict Tactics Scales (CTS2) development and preliminary psychometric data. J Fam Issues 17(3):283-316

Straus MA (1979) Measuring intrafamily conflict and violence: the Conflict Tactics (CT) Scales. J Marriage Fam 41(1):75-88

Straus MA (2007) Conflict Tactics Scales. In: Jackson NA (ed) Encyclopedia of domestic violence. Routledge, New York, NY, p 190-197

Walby S, Towers J, Balderston S, Corrado C, Francis B, Heiskanen M, HelwigLarson K, Mergaert L, Olive P, Palmer E, Stöck 1, Strid S (2017) The concept and measurement of violence against women and men. Policy Press, Bristol

Walby S, Myhill A (2001) New survey methodologies in researching violence against women. British Journal of Criminology 41:502-522

Witkins S, Harrison D (2001) Whose evidence and for what purpose? Social Work 46(4.1):293-296

Wylie A (1987) The philosophy of ambivalence: Sandra Harding on the science question in feminism. Canadian J Philos 17(1):58-73

Yates S (2018) Power, process, plumbing: Big G and Small g gender in Victoria's family violence policy subsystem. Australian J Public Admin. https://doi.org/ 10.1111/1467-8500.12265

Young K, Ashby D, Boaz A, Grayson L (2002) Social science and the evidencebased policy movement. Social Policy Soc 1(3):215-224

\section{Data availability}

Data sharing not applicable as no datasets were analysed or generated.

\section{Additional information}

Competing interests: The authors declare no competing interests.

Reprints and permission information is available online at http://www.nature.com/ reprints

Publisher's note: Springer Nature remains neutral with regard to jurisdictional claims in published maps and institutional affiliations.

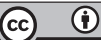

Open Access This article is licensed under a Creative Commons Attribution 4.0 International License, which permits use, sharing, adaptation, distribution and reproduction in any medium or format, as long as you give appropriate credit to the original author(s) and the source, provide a link to the Creative Commons license, and indicate if changes were made. The images or other third party material in this article are included in the article's Creative Commons license, unless indicated otherwise in a credit line to the material. If material is not included in the article's Creative Commons license and your intended use is not permitted by statutory regulation or exceeds the permitted use, you will need to obtain permission directly from the copyright holder. To view a copy of this license, visit http://creativecommons.org/ licenses/by/4.0/

(c) The Author(s) 2018 